\title{
Inovasi pengembangan TPQ menjadi pusat studi tajwid menggunakan metode nasyid berbantuan articulate storyline
}

\section{Siti Khoiruli Ummah ${ }^{1 *}$, Safira Rahmadita Ismara², Devi Mellysapitri ${ }^{3}$, L. Yasril Imam ${ }^{4}$, Muhammad Natsir Hentihu ${ }^{5}$}

${ }^{1}$ Universitas Muhammadiyah Malang, Indonesia, email: khoiruliummah@umm.ac.id

2Universitas Muhammadiyah Malang, Indonesia, email: safiralp96@gmail.com

${ }^{3}$ Universitas Muhammadiyah Malang, Indonesia, email: devimellysapitri2000@gmail.com

${ }^{4}$ Universitas Muhammadiyah Malang, Indonesia, email: yasrilimam98@gmail.com

${ }^{5}$ Universitas Muhammadiyah Malang, Indonesia, email: hentihu.natsir@gmail.com

*Koresponden penulis

\section{Info Artikel}

Diajukan: 27 Jan 2021

Diterima: 16 Jul 2021

Diterbitkan: 30 Jul 2021

Keywords:

tajweed center; articulate

storyline; TPQ; nasyeed

Kata Kunci:

pusat studi tajwid; articulate storyline; TPQ; nasyid

Lisensi:

cc-by-sa

\begin{abstract}
The aim of this article is to describe how implementing a mentoring program in e-tutorials in learning tajweed. Learning tajweed is done by the method nasheed where nasheed and the whole of the material tajweed put on the application of Articulate Storyline. The method of implementation of the program is done online using the help of Zoom for 10 meetings. As for the phases of the program starting with giving pretest then mentoring including socialization, pretest, training, posttest and evaluation. The target programs are masjeed tenager who will organize TPQ for future program. The results of the implementation of the program, namely the passage of the program according to the schedule. In addition, there is an increasing understanding of tajweed by $85 \%$ through the scores of pretest and posttest obtained. Testimonials partners very well, especially in terms of the practicality of the media, interest, and understanding. The sustainability of this program is learning tajweed online via Live Instagram assisted by ustadz.
\end{abstract}

Abstrak

Tujuan dari penulisan artikel ini adalah menjelaskan bagaimana memberdayakan TPQ menjadi pusat studi tajwid menggunakan metode e-nasyid berbantuan Articulate Storyline. TPQ memerlukan bantuan agar mempunyai inovasi dalam pembelajaran tajwid selama masa pandemi. Metode penerapan program dilakukan secara online diawali dengan pretest terkait pemahaman tajweed kemudian pelatihan menggunakan bantuan Zoom untuk 10 pertemuan. Sasaran mitra program adalah remaja masjid agar mampu mengelola TPQ sebagai bahan keberlanjutan program. Adapun fase dari program diantaranya sosialisasi, pretest, pelatihan, post-tes dan evaluasi. Hasil dari implementasi program, yaitu pemaparan hasil di setiap tahapan program. Selain itu, ada peningkatan pemahaman tajwid dengan skor 85\% melalui skor prettest dan posttest. Respon mitra sangat baik, terutama dalam hal kepraktisan media, kemenarikan, dan pemahaman. Tindak lanjut program ini adalah pembelajaran tajwid melalui Instagram dalam bentuk Live dengan ustadz dengan cakupan peserta pusat studi tajwid lebih banyak. 


\section{PENDAHULUAN}

Permasalahan yang dihadapi anak-anak selama pandemi yaitu perlunya kegiatan pembelajaran mengaji dan tajwid di TPQ. Namun, dalam kondisi pandemi, TPQ tidak diperbolehkan melaksanakan pembelajaran secara luring. $\mathrm{Hal}$ ini sangat bertolak belakang dengan hasil program penelitian dan pengabdian yang telah dilakukan sebelumnya, dimana fase anak-anak merupakan tahapan krusial dalam mempelajari tajwid karena kurangnya antusias anak dalam mempelajarinya (Hambali et al., 2021). Pelafalan dan penggunaan hukum tajwid masih termasuk sulit untuk diterapkan (Waslah et al., 2020). Hal ini terlihat di TPQ Shirotol Mustaqim ketika anak-anak yang membaca Al-Quran seringkali belum mampu melafalkan huruf "sin" dan "syin" dengan benar. Selain itu, anak-anak juga seringkali kurang dapat membedakan "idgham" dan "ikhfa". Setelah dilakukan penelusuran, kesulitan dialami ketika anak tidak mampu menghafal hukum nun sukun atau tanwin dan membedakannya ketika membaca Al-Quran. Oleh sebab itu, terdapat beberapa program pengabdian untuk mengatasinya, misalkan memberikan pelatihan online menggunakan audiovisual, berbasis Android, web, atau memberikan modul bergambar dan berwarna agar lebih menarik dalam mempelajarinya (Hambali et al., 2021; Permatasari \& Falah, 2014; Suryani et al., 2016; Waslah et al., 2020).

Tempat Pendidikan Quran (TPQ) merupakan pusat studi untuk mempelajari Qur'an baik dari aspek pengenalan huruf hijaiyah, hukum tajwid, tartil maupun qiroah. Anak didik TPQ sangat bervariasi, mulai kategori anakanak remaja, hingga dewasa. TPQ Shirotol Mustaqim berlokasi di Desa Baamang Tengah, Kabupaten Kotawaringin, Provinsi Kalimantan Tengah. TPQ ini mempunyai banyak anak didik. Kondisi pandemi yang terjadi di Indonesia sejak Bulan Maret Tahun 2020 mengakibatkan ditiadakannya kegiatan pembelajaran di TPQ. Ustadz berkunjung dari rumah ke rumah untuk mengajar mengaji secara pribadi. Anak didik mengeluh terlalu lama untuk mengaji dengan metode privat dan kurang bersemangat karena tidak ada teman untuk berkompetisi untuk setiap progress mengaji. Padahal, anak didik memerlukan metode untuk belajar mengaji, khususnya ilmu tajwid yang mudah dan praktis untuk diakses kapanpun. Hal ini belum dapat dipenuhi oleh TPQ Shirotol Mustaqim karena TPQ belum menyediakan metode seperti yang diperlukan anak didik tersebut.

IImu Tajwid merupakan salah satu bagian dari materi yang diajarkan di TPQ. Umat muslim yang membaca Al-Quran tanpa menggunakan tajwid dengan baik akan mendapat dosa. Hal ini dikarenakan Al-Quran diturunkan oleh Allah SWT sekaligus dengan tajwid yang dimuatnya (Suryani et al., 2016). Pengembangan media untuk mempelajari tajwid sebelumnya menggunakan aplikasi berbasis Android terbukti mampu menambah pemahaman (Satria et al., 2015) dan mempermudah dalam mempelajari tajwid secara fleksibel (Permatasari \& Falah, 2014; Sudiarjo et al., 2015).

Pengabdian dalam bentuk pemberdayaan TPQ dan peningkatan kualitas TPQ sebelumnya lebih terfokus pada manajemen operasional TPQ (Malik, 2013), pendidikan karakter religious (Hidayah et al., 2019), penguatan 
SDM (Ajhuri \& Saichu, 2018), tata kelola dan Baca Tulis Quran (Syaharuddin et al., 2018). Perbedaan dengan program pengabdian kepada masyarakat sebelumnya yaitu program pengabdian kepada masyarakat ini difokuskan pada pendirian pusat studi tajwid menggunakan metode nasyid dan terintegrasi dengan teknologi. Teknologi yang dimaksud disini yaitu pembuatan aplikasi dengan menggunakan Articulate Storyline. Aplikasi Articulate Storyline dipilih karena mempunyai kemudahan dalam pengoperasian dan hasil yang ditampilkan lebih menarik (Hadza et al., 2020; Hamzah et al., 2015; Hassan et al., 2012; Yahya et al., 2020). Wujud dari Articulate Storyline yaitu berupa video e-tutorial yang memuat pembelajaran ilmu tajwid dan memuat nasyid untuk memudahkan hafalan hukum tajwidnya.

Pembelajaran online mempunyai karakteristik utama yaitu adanya integrasi dengan teknologi berupa forum diskusi secara chat maupun forum diskusi yang dilakukan dengan cara tatap muka secara online sehingga terdapat interaksi antar pebelajar. Lingkungan pembelajaran secara online menuntut adanya interaksi sosial tetap ditekankan meskipun terdapat jarak secara geografis (Maré \& Mutezo, 2020). E-tutoring merupakan kegiatan belajar dan mengajar yang dilakukan secara online menggunakan fasilitas internet. Manfaat yang bisa diperoleh dari kegiatan e-tutoring yaitu kepraktisan karena peserta dan tutor berada di rumah masing-masing serta dapat diakses sewaktu-waktu (McGuinness \& Fulton, 2019).

IImu tajwid merupakan hal yang bersifat wajib ketika umat Islam membaca Al-Quran. Program pembelajaran IImu tajwid ini mengadopsi materi ilmu tajwid diantaranya makhorijul huruf, musta haqqul harf, hukum mad, hukum nun sukun dan tanwin, hukum mim sukun, hukum nun bertasydid, qalqalah, dan hukum alif lam (Suryani et al., 2016).

Nasyid merupakan salah satu kegiatan dalam ajaran Islam yang digunakan untuk berdakwah dimana pesan-pesan dakwah dijadikan lirik lagu (Satria \& Mohamed, 2017). Melalui nasyid, manusia dapat belajar dengan kondisi yang rileks (Kadir et al., 2010). Nasyid merupakan metode dakwah yang sangat disukai karena mudah diingat dan tidak membosankan (Yanti, 2016).

Permasalahan utama yang akan diselesaikan yaitu pemberian e-tutorial kepada anak didik TPQ melalui metode nasyid berbantuan Articulate Storyline. Tujuan diadakannya program e-tutorial ini yaitu untuk meningkatkan pemahaman anak didik terhadap ilmu tajwid melalui metode nasyid berbantuan Articulate Storyline dan menjadikan TPQ Shirotol Mustaqim sebagai pusat studi ilmu tajwid yang terintegrasi teknologi. Hal ini akan menambah kualitas TPQ dari aspek metode pembelajaran sehingga dapat diakses oleh masyarakat di luar daerah melalui e-tutorial. Pemilihan lokasi pusat studi tajwid di TPQ Shirotol Mustaqim berdasarkan permintaan dari masyarakat untuk penyelenggaraan pembelajaran tajwid secara online. Karena kondisi pandemi, beberapa TPQ memilih tutup sehingga hanya ustadz di TPQ Shirotol Mustaqim yang bersedia mengirimkan santrinya, dalam hal ini remaja masjid, yang sebelumnya sangat aktif dalam pengembangan program TPQ.

Pemberdayaan yang dilakukan pada program ini menggunakan strategi e-tutorial menggunakan aplikasi Zoom berbantuan Articulate Storyline yang 
menjadi inovasi dari pengembangan pusat studi tajwid ini. Seperti telah dijelaskan sebelumnya, pelatihan tajwid berupa media audiovisual, nyanyian, buku bergambar, media berbasis web, dan Android sudah dilakukan sebelumnya (Hambali et al., 2021; Permatasari \& Falah, 2014; Satria et al., 2015; Suryani et al., 2016). Kebaruan program pengabdian ini terletak pada keberlanjutan program dimana TPQ akan dibentuk menjadi pusat studi tajwid secara online dengan menggunakan bantuan media Articulate Storyline. Metode e-tutorial dalam mempelajari ilmu tajwid diwujudkan dalam bentuk lirik dan lagu nasyid agar mudah diingat. Rekaman nasyid dalam bentuk MP3 kemudian dianimasikan menggunakan aplikasi Articulate Storyline.

Manfaat pelaksanaan program dalam bentuk e-tutorial yaitu menambah kualitas TPQ, memperbanyak anak didik TPQ, dan menambah pemahaman anak didik tentang ilmu tajwid. Selain itu, diadakannya e-tutorial ini dapat membuat masyarakat tertarik mempelajari ilmu tajwid yang praktis, mudah dan dapat diakses melalui gadget. E-tutorial juga mempunyai fasilitas pretest dan posttest sehingga anak didik yang lulus sesuai kriteria akan mendapatkan esertifikat.

\section{METODE PELAKSANAAN}

Program pemberdayaan TPQ sebagai pusat studi ilmu tajwid ini merupakan hasil pelaksanaan Program Kreativitas Mahasiswa (PKM) Pendanaan Tahun 2020 yang didanai oleh Kementerian Pendidikan dan Kebudayaan dan telah mencapai PIMNAS. Metode pelaksanaan dari kegiatan pemberdayaan ini yaitu sosialisasi, pelatihan dan pendampingan kepada mitra. Adapun mitra kegiatan ini yaitu remaja masjid Shirotol Mustaqim dengan rentang usia 15-20 tahun, berjumlah 7 orang, yang menjadi pengurus masjid. Rancangan kegiatan untuk menyelesaikan masalah sulitnya belajar tajwid dilaksanakan dengan kegiatan sebagai berikut:

1. Sosialisasi e-tutorial

Sosialisasi ini bertujuan untuk memberikan pengarahan kepada mitra tentang teknis pelatihan dan penggunaan media articulate storyline sebagai bahan pelatihan tajwid menggunakan metode nasyid. Pelaksanaan sosialisasi secara online menggunakan aplikasi Zoom dengan melibatkan ustadz selaku penanggung jawab TPQ, tim pengabdian (tim PKM) dan mitra program.

2. Kegiatan pretest

Pretest dilakukan untuk mengidentifikasi kemampuan awal mitra terkait tajwid. Pretes berfokus pada pengetahuan tentang hukum nun mati atau tanwin, hukum mim sukun, dan qalqalah.

3. Kegiatan pelatihan

Pelatihan dilaksanakan sebanyak enam kali dengan deskripsi kegiatan dapat dilihat pada Tabel 1. Pelaksanaan pelatihan secara online menggunakan aplikasi Zoom.

4. Kegiatan posttest

Postest dilaksanakan secara online menggunakan Google Form dengan materi yang sama dengan pretest 
5. Kegiatan penutup

Kegiatan penutup dilakukan dengan melakukan refleksi terkait hal-hal yang perlu dievaluasi terkait kelancaran media, penggunaan buku pelaksanaan program dan pengkaderan.

Tabel 1. Deskripsi implementasi kegiatan

\begin{tabular}{|c|c|c|}
\hline $\begin{array}{l}\text { Pertemuan } \\
\text { ke- }\end{array}$ & Kegiatan & Keterlibatan Mitra \\
\hline 1 & Pretest & Mitra membaca ayat Al-Quran \\
\hline 2 & $\begin{array}{l}\text { Pelatihan pelafalan huruf } \\
\text { Hijaiyah }\end{array}$ & $\begin{array}{l}\text { Mitra mengakses Articulate Storyline dan menirukan } \\
\text { nasyid }\end{array}$ \\
\hline 3 & $\begin{array}{l}\text { Pelatihan Nun sukun } \\
\text { dan/tanwin }\end{array}$ & $\begin{array}{l}\text { Mitra mengakses Articulate Storyline dan menirukan } \\
\text { nasyid }\end{array}$ \\
\hline 4 & Hukum Mim Sukun & $\begin{array}{l}\text { Mitra mengakses Articulate Storyline dan menirukan } \\
\text { nasyid }\end{array}$ \\
\hline 5 & Ikhfa' Syafawi & $\begin{array}{l}\text { Mitra mengakses Articulate Storyline dan menirukan } \\
\text { nasyid }\end{array}$ \\
\hline 6 & Hukum Mad & $\begin{array}{l}\text { Mitra mengakses Articulate Storyline dan menirukan } \\
\text { nasyid }\end{array}$ \\
\hline 7 & Hukum Mad & $\begin{array}{l}\text { Mitra mengakses Articulate Storyline dan menirukan } \\
\text { nasyid }\end{array}$ \\
\hline
\end{tabular}

Tabel 1 menunjukkan tahapan pelaksanaan program pelatihan sampai TPQ siap menjadi pusat studi tajwid. Mitra dalam hal ini adalah pengelola TPQ dan remaja masjid yang menjadi tutor dalam kegiatan mengaji di TPQ tersebut.

Target program e-tutorial ini antara lain mitra memahami ilmu Tajwid melalui nasyid dan mitra mampu mengakses Articulate Storyline. Target ini akan dilihat dari adanya peningkatan kemampuan pemahaman tajwid melalui nilai $\mathrm{N}$ gain yang diperoleh dari skor pretest dan posttest. Apabila nilai N-Gain mencapai $75 \%$ maka dianggap meningkat dan mitra telah dianggap mampu mengimplementasikan metode e-nasyid selama pembelajaran tajwid di pusat studi tajwid.

Metode yang dilaksanakan dalam menjalankan program yaitu e-tutorial dengan cara tim melakukan share screen media Articulate Storyline kepada mitra melalui Zoom.

\section{HASIL DAN PEMBAHASAN}

Kegiatan diawali dengan pembuatan media melalui Articulate Storyline selama 3 minggu di Bulan Agustus Tahun 2020. Tim mencari referensi terlebih dahulu materi hukum tajwid secara online pada buku hukum tajwid. Tim kemudian memutuskan hukum tajwid yang dimasukkan antara lain idzhar, idgham bigunnah, idgham bilagunnah, dan hukum mad.

Tahapan selanjutnya yaitu penentuan objek yang dibuat pada Articulate Storyline yaitu huruf arab, tombol, pembuatan karakter berupa kartun, dan background. Objek dibuat menggunakan Adobe Premiere dan Adobe Photoshop. Setelah objek terbentuk, objek dimasukkan pada Articulate Storyline. Tim selanjutnya membuat lirik nasyid dan lagu nasyid untuk kemudian dilakukan perekaman dengan format MP3. Selanjutnya, MP3 berhasil di import pada menu Articulate Storyline dan dihubungkan pada tombol. Setiap tombol 
nantinya difungsikan agar terhubung ke halaman lainnya. Contoh tampilan enasyid dapat dilihat pada Gambar 1.

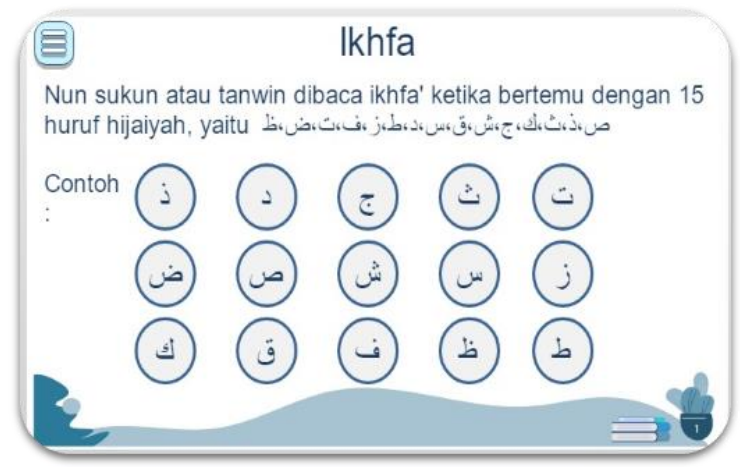

Gambar 1. Tampilan E-Nasyid

Kegiatan sosialisasi dilakukan secara online dengan 6 anak didik TPQ Shirotol Mustaqim pada Bulan September Tahun 2020. Tim memaparkan inti kegiatan selama program dijalankan kepada mitra diawali dengan sapaan dan tanya-jawab serta review materi hukum tajwid yang dipahami mitra sebelum kegiatan pelatihan dimulai. Kegiatan ini sesuai dengan kegiatan pengabdian sebelumnya, yang menceritakan bahwa kegiatan sosialisasi penting dilakukan agar mitra dapat mengikuti kegiatan dengan baik (Hidayah et al., 2019). Hasil kegiatan sosialisasi yaitu mitra masih belum dapat menerapkan idghom bigunnah dengan baik, dilihat dari cara mitra melafalkan bacaan yang memuat idghom bigunnah dengan cara mendengung. Selain itu, mitra juga mengeluh bahwa mitra belum hafal huruf-huruf yang termasuk dalam hukum ikhfa' dan hukum idghom bigunnah. Mitra bersedia mengikuti program melalui e-tutorial menggunakan aplikasi Zoom.

Pelatihan selanjutnya dilakukan dengan kegiatan pretest. Mitra diminta untuk membaca ayat Quran yang memuat hukum idghom bigunnah. Hasil pretest menunjukkan mitra masih kurang bisa membedakan hukum ikhfa' dengan hukum bighunnah. Mitra selanjutnya diberikan tanya-jawab tentang huruf-huruf yang memenuhi hukum idzhar dan alif lam. Sebanyak $80 \%$, mitra belum mampu menyebutkan huruf-huruf yang memenuhi hukum ikhfa' dan idgham bighunnah. Kegiatan pretest dilakukan secara online dengan menekankan pada praktik membaca dan tanya-jawab mempunyai kemiripan wujud kegiatan dengan program pengabdian sebelumnya yaitu menggunakan metode tanya-jawab. Hasil kegiatan pretest yaitu sebanyak 1 orang yang mampu menjawab dan melafalkan ayat Al-Quran dengan tepat dan lancar.

Pertemuan ketiga melalui Zoom memuat materi hukum idzhar. Penyampaian materi dilakukan dengan cara share screen aplikasi Articulate Storyline kepada mitra sehingga tim Hasil kegiatan ini yaitu mitra mengamati dan mengakses media. Di akhir kegiatan, mitra diminta membaca ayat Al-Quran secara acak untuk mengecek dan merevisi bacaan hukum tajwid dari mitra. Kegiatan tanya-jawab dan simulasi membaca tajwid merupakan salah satu 
bentuk posttest yang digunakan untuk mengevaluasi keberlanjutan program. Pelaksanaan posttest yang dilakukan secara online. Hal ini dilakukan dengan cara tim meminta mitra membaca ayat Al-Quran yang memuat hukum tajwid yang dipelajari pada pertemuan tersebut, meminta mitra mencari ayat Al-Quran yang memuat hukum tajwid dan memberikan pertanyaan terkait hukum tajwid.

Testimoni mitra merupakan faktor yang mempengaruhi baik tidaknya program ini. Mitra menyampaikan bahwa program ini sangat layak untuk dipublikasikan di masyarakat luas karena pembelajaran tajwid yang sangat praktis untuk diakses di berbagai platform dan fleksibel untuk waktu pengaksesannya. Mitra sangat antusias dan semangat untuk mengikuti pelatihan karena terkadang posttest dilakukan dengan sistem tebak-tebakan oleh tim.

Hasil program pemberdayaan yang telah dilaksanakan yaitu terbentuknya kader atau pengelola pusat studi tajwid di TPQ Shirotol Mustaqim dimana kegiatan dari pusat studi ini berfokus pada pembelajaran tajwid dengan metode nasyid. Adapun pembelajaran tajwid dilaksanakan secara online dengan menggunakan bantuan media e-nasyid berbentuk tutorial. Hasil lain dari program ini yaitu peningkatan pemahaman mitra terkait tajwid dengan perolehan nilai $\mathrm{N}$-Gain yaitu $85 \%$. Selain itu, hasil pelatihan pembentukan pusat studi tajwid memberikan antusias yang baik dari mitra dengan cara keikutsertaan dan kesediaan mitra mengelola pusat studi tajwid ini secara online. Adapun hasil pretes dan postes dapat dilihat pada Tabel 2.

Tabel 2. Perolehan Hasil Pretest dan Posttest

\begin{tabular}{|c|c|c|c|c|c|c|c|c|c|c|}
\hline \multirow[b]{2}{*}{ No. } & \multirow[b]{2}{*}{ Nama } & \multicolumn{2}{|c|}{ PRETEST } & \multicolumn{2}{|c|}{ POSTTEST } & \multirow{2}{*}{$\begin{array}{c}\text { Posttest- } \\
\text { Pretest }\end{array}$} & \multirow{2}{*}{$\begin{array}{c}\text { Skor } \\
\text { Ideal } \\
\text { Pretest }\end{array}$} & \multirow{2}{*}{$\begin{array}{l}\text { N-Gain } \\
\text { Skor }\end{array}$} & \multirow{2}{*}{$\begin{array}{c}\text { N-Gain } \\
\text { Skor } \\
(\%)\end{array}$} & \multirow[b]{2}{*}{ Keterangan } \\
\hline & & Nilai & Ket. & Nilai & Ket. & & & & & \\
\hline 1 & A & 50 & Cukup & 90 & Sempurna & 40 & 50 & 0.80 & 80 & BAIK \\
\hline 2 & B & 53 & Cukup & 93 & Sempurna & 40 & 47 & 0.85 & 85 & SEMPURNA \\
\hline 3 & $C$ & 51 & Cukup & 91 & Sempurna & 40 & 49 & 0.82 & 82 & SEMPURNA \\
\hline 4 & D & 51 & Cukup & 95 & Sempurna & 44 & 49 & 0.90 & 90 & SEMPURNA \\
\hline 5 & E & 52 & Cukup & 94 & Sempurna & 42 & 48 & 0.88 & 88 & SEMPURNA \\
\hline 6 & $\mathrm{~F}$ & 53 & Cukup & 92 & Sempurna & 39 & 47 & 0.83 & 83 & SEMPURNA \\
\hline 7 & $\mathrm{G}$ & 50 & Cukup & 90 & Sempurna & 40 & 50 & 0.80 & 80 & BAIK \\
\hline 8 & $\mathrm{H}$ & 65 & Baik & 98 & Sempurna & 33 & 35 & 0.94 & 94 & SEMPURNA \\
\hline 9 & 1 & 55 & Cukup & 92 & Sempurna & 37 & 45 & 0.82 & 82 & SEMPURNA \\
\hline 10 & $\mathrm{~J}$ & 50 & Cukup & 91 & Sempurna & 41 & 50 & 0.82 & 82 & SEMPURNA \\
\hline \multicolumn{8}{|c|}{ Rata-Rata } & 0.85 & 85 & \\
\hline
\end{tabular}

Tabel 2 menunjukkan bahwa mitra mempunyai kenaikan yang signifikan terkait pemahaman tajwid. Hal ini ditunjukkan dengan kategori kelulusan postes yaitu mencapai sempurna. Perolehan $\mathrm{N}$-Gain menggunakan rumus $N$ Gain =

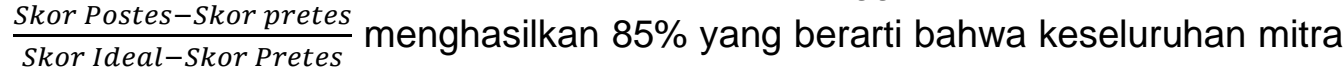
mempunyai peningkatan pemahaman konsep tajwid dengan sangat baik.

Keberlanjutan program yaitu dipublikasikannya program melalui Instagram. Program akan dilaksanakan dengan cara memberikan pelatihan bersertifikat. Hal ini akan dilakukan dengan menggunakan alur pelatihan yaitu: 
1. Registrasi

Registrasi dilakukan secara online dimana mitra akan mengisi Google Form yang sudah dibagikan melalui Feed Instagram. Setelah registrasi sukses, peserta akan mendapat email berupa data profil diri dan jadwal pelatihan.

2. Pretest

Pretest dilakukan secara online melalui video call dengan Ustadz TPQ Shirotol Mustaqim sesuai jadwal. Hasil pretest berupa skor dan deskripsi dari indikator Makhorijul huruf, kelancaran, dan ketepatan dikirimkan melalui email.

3. Pelatihan

Pelatihan dilakukan selama 10 kali pertemuan dengan hukum tajwid yang berbeda di setiap pertemuan. Peserta akan diberikan akses media Articulate Storyline kemudian setiap minggu diadakan evaluasi tentang apa yang dipelajari mitra dalam satu minggu. Ustadz juga akan memaparkan materi melalui Live IG tentang tajwid dan ayat Al-Quran kemudian menjelaskan hukum tajwid apa saja yang termuat pada ayat tersebut. Tanya-jawab dilakukan melalui Live IG ketika ada mitra yang mengkonfirmasi melalui chat.

4. Posttest

Posttest dilakukan dengan cara video conference antara ustadz dengan mitra secara pribadi.

5. Penerimaan e-sertifikat

E-sertifikat akan diberikan kepada mitra melalui email.

Keberhasilan program diukur dari adanya peningkatan pemahaman ilmu tajwid dan testimoni mitra tentang keterlaksanaan program. Hal ini sejalan dengan pengabdian sebelumnya yang menyatakan bahwa keberhasilan program ditinjau dari adanya peningkatan kemampuan, testimoni positif dari mitra, serta keberlanjutan program yang berpotensi baik.

\section{KESIMPULAN}

Program pemberdayaan TPQ menjadi pusat studi tajwid dengan metode nasyid berbantuan Articulate Storyline berjalan dengan lancar. Kendala yang terjadi lebih banyak pada sinyal internet yang mengganggu jalannya video conference. Pembelajaran tajwid mendapatkan testimoni yang baik dari mitra dimana mitra sangat antusias mengikuti tahapan program pada pertemuan selanjutnya. Mitra juga mengemukakan kalau dengan menghafalkan nasyid, maka huruf-huruf yang sesuai dengan hukum tajwid menjadi mudah untuk dihafalkan. Peningkatan pemahaman mitra diukur dari hasil pretest dan posttest sebesar $85 \%$ sesuai indikator Makhorijul huruf, ketepatan, dan kelancaran membaca ayat Al-Quran sesuai hukum tajwid yang berlaku.

Saran program selanjutnya yaitu adanya program lain selain pembelajaran tajwid, misalnya qiroah maupun tartil. Selain itu, program ini dapat diperluas ke luar daerah untuk dilakukan secara online. Aplikasi dapat dikembangkan sehingga dapat diakses dan didownload melalui Playstore. 


\section{UCAPAN TERIMA KASIH}

Ucapan terima kasih disampaikan kepada Direktorat Pembelajaran dan Kemahasiswaan, Direktorat Jenderal Pendidikan Tinggi, Kementerian Pendidikan dan Kebudayaan yang telah memberikan hibah dalam bentuk Program Kreativitas Mahasiswa. Terima kasih juga disampaikan atas dukungan dan bantuan pendanaan kepada Bidang Kemahasiswaan Universitas Muhammadiyah Malang.

\section{DAFTAR RUJUKAN}

Ajhuri, K. F., \& Saichu, M. (2018). Pemberdayaan Taman Pendidikan Al-Quran ( TPQ ) melalui Penguatan SDM di Masjid Nurul Fikri Watu Bonang, Badegan, Ponorogo. QALAMUNA-Jurnal Pendidikan, Sosial, Dan Agama, 10(2), 175-195. https://doi.org/10.5281/zenodo.3559271

Hadza, C., Sesrita, A., \& Suherman, I. (2020). Development of Learning Media Based on Articulate Storyline. Indonesian Journal of Applied Research (IJAR), 1(2), 80-85. https://doi.org/10.30997/ijar.v1i2.54

Hambali, H., Rozi, F., \& Farida, N. (2021). Pengelolaan Pembelajaran IImu Tajwid Melalui Media Audio Visual. NATURALISTIC: Jurnal Kajian Penelitian Pendidikan Dan Pembelajaran, 5(2), 872-881. https://doi.org/10.35568/naturalistic.v5i2.1180

Hamzah, W. M. A. F. W., Ali, N. H., Saman, M. Y. M., Yusoff, M. H., \& Yacob, A. (2015). The use of Tin Can API for web usage mining in E-learning applications on the social network. 2015 IEEE Symposium on Computer Applications \& Industrial Electronics (ISCAIE), 113-118. https://doi.org/10.1109/ISCAIE.2015.7298338

Hassan, H., Hassan, F., Omar, N. D. @, Zakaria, Z., \& Nor, W. A. W. M. (2012). Evaluating Mathematics e-Learning Materials: Do Evaluators Agree with Distance Learners? The 3rd International Conference on E-Learning (ICEL), 67, 189-195. https://doi.org/10.1016/j.sbspro.2012.11.320

Hidayah, Y., Suyitno, \& Retnasari, L. (2019). Pemberdayaan Taman Pendidikan Al-Quran ( TPA ) Sebagai Pusat Pendidikan Karakter Religus ( Pengabdian di TPQ Silastra Condong Catur, TPQ Darul Falah Maguwo Harjo. LOYALITAS Jurnal Pengabdian Kepada Masyarakat, 2(2), 1320. https://doi.org/10.30739/loyal.v2i2.489

Kadir, R. S. S. A., Ghazali, M. H., Murat, Z. H., Taib, M. N., Rahman, H. A., \& Aris, S. A. M. (2010). The preliminary study on the effect of nasyid music and rock music on brainwave signal using EEG. 2010 2nd International Congress on Engineering Education, 58-63. https://doi.org/10.1109/ICEED.2010.5940764

Malik, H. A. (2013). Pemberdayaan Taman Pendidikan Al-Qur'an (TPQ) ALhusna Pasadena Semarang. Dimas: Jurnal Pemikiran Agama Untuk Pemberdayaan, 13(2), https://doi.org/10.21580/dms.2013.132.60

Maré, S., \& Mutezo, A. T. (2020). The effectiveness of e-tutoring in an open and distance e-learning environment: evidence from the university of south africa. Open Learning: The Journal of Open, Distance and e-Learning, 
36(2), 164-180. https://doi.org/10.1080/02680513.2020.1717941

McGuinness, C., \& Fulton, C. (2019). Digital Literacy in Higher Education: A Case Study of Student Engagement with E-Tutorials Using Blended Learning. Journal of Information Technology Education: Innovations in Practice, 18, 1-28. https://doi.org/10.28945/4190

Permatasari, D., \& Falah, A. (2014). Aplikasi Pembelajaran Ilmu Tajwid Berbasis Android (Studi Kasus: Madrasah Ar - Rahman Bandung). JATI Jurnal Teknologi Dan Informasi, 4(1). https://doi.org/10.34010/jati.v4i1.802

Satria, E., \& Mohamed, R. (2017). Analisis Terhadap Peranan Nasyid Dalam Dakwah. Jurnal IImiah ISLAM FUTURA, 16(2), 227-242. https://doi.org/10.22373/jiif.v16i2.1329

Satria, E., Tresnawati, D., \& Nurvitrya, A. (2015). Pengembangan Aplikasi Pembelajaran Iqra' dan Tajwid Berdasarkan Metode Asy-Syafi'i Menggunakan Sistem Multimedia. Jurnal Algoritma, 12(1), 74-81. https://doi.org/10.33364/algoritma/v.12-1.74

Sudiarjo, A., Mariana, A. R., \& Nurhidayat, W. (2015). Aplikasi Pembelajaran IImu Tajwid, Waqaf dan Makharijul Huruf Berbasis Android. Jurnal Sisfotek Global, 5(2), 54-60. https://doi.org/10.38101/sisfotek.v5i2.80

Suryani, D., Irfan, M., Uriawan, W., \& Zulfikar, W. B. (2016). Implementasi Algoritma Divide And Conquer Pada Aplikasi Belajar Ilmu Tajwid. Jurnal Online Informatika, 1(1), 13-19. https://doi.org/10.15575/join.v1i1.5

Syaharuddin, Mandailina, V., Riadi, \& Mahsup. (2018). Peningkatan Manajemen Tata Kelola dan Metode Baca Tulis Al Qur'an Guru dan Santri Kelompok TPQ di Lombok Tengah NTB. Jurnal Pemberdayaan Masyarakat Berkarakter, 1(1), 10-19. https://journal-litbangrekarta.co.id/index.php/jpmb/article/view/12

Waslah, Chotimah, C., Hasanah, F., \& A., M. A. M. (2020). Pelatihan Pembelajaran Tajwid di TPQ Al Hidayah Desa Brodot Jombang. Jumat Keagamaan: Jurnal Pengabdian Masyarakat, 1(1), 21-24. https://ejournal.unwaha.ac.id/index.php/abdimas_agama/article/view/1 062

Yahya, R., Ummah, S. K., \& Effendi, M. M. (2020). Pengembangan Perangkat Pembelajaran Flipped Classroom Bercirikan Mini-Project. SJME (Supremum Journal of Mathemathics Education), 4(1), 78-91. https://doi.org/10.35706/sjme.v4i1.3136

Yanti, F. (2016). Komunikasi Dakwah dalam Kesenian Nasyid. Al-Mishbah: Jurnal IImu Dakwah Dan Komunikasi, 12(2), 211-231. http://www.almishbahjurnal.com/index.php/al-mishbah/article/view/71 